\title{
Phosphodiesterase inhibition induces retinal degeneration, oxidative stress and inflammation in cone-enriched cultures of porcine retina
}

\author{
Q4 Cristina Martínez-Fernández de la Cámara ${ }^{\mathrm{a}}, \mathrm{M}^{\mathrm{a}}$ - Dolores Sequedo ${ }^{\mathrm{a}}$, Ulises Gómez-Pinedo ${ }^{\mathrm{b}}$, \\ Teresa Jaijo ${ }^{\mathrm{a}, \mathrm{c}}$, Elena Aller ${ }^{\mathrm{a}, \mathrm{c}}$, Patricia García-Tárraga ${ }^{\mathrm{d}}$, José Manuel García-Verdugo ${ }^{\mathrm{d}}$, \\ José María Millán ${ }^{\mathrm{a}, \mathrm{c}, \mathrm{e}}$, Regina Rodrigo ${ }^{\mathrm{a}, *}$ \\ Q1 a Laboratory of Sensorineural Disorders, Instituto de Investigación Sanitaria-La Fe, Avda. Campanar, 21, 46009 Valencia, Spain

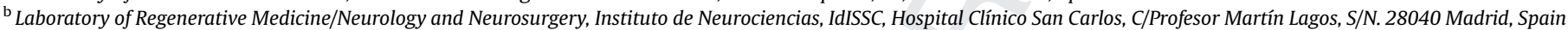 \\ ${ }^{\mathrm{C}}$ Centre for Biomedical Network Research on Rare Diseases, Valencia, Spain

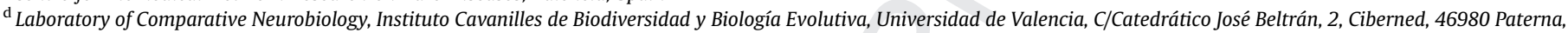 \\ València, Spain \\ ${ }^{\mathrm{e}}$ Genetics Unit, Hospital Universitario La Fe, Avda. Campanar, 21, 46009 Valencia, Spain
}

\section{A R T I C L E I N F O}

\section{Article history:}

Received 19 September 2012

Accepted in revised form 19 March 2013

Available online $\mathrm{xxx}$

\section{Keywords:}

retinal degeneration

cGMP

Zaprinast

oxidative stress

TNF-alpha

poly (ADP-ribose)

caspase

retinitis pigmentosa

photoreceptor death

\begin{abstract}
A B S T R A C T
Inherited retinal degenerations affecting both rod and cone photoreceptors constitute one of the causes of incurable blindness in the developed world. Cyclic guanosine monophosphate (cGMP) is crucial in the phototransduction and, mutations in genes related to its metabolism are responsible for different retinal dystrophies. cGMP-degrading phosphodiesterase 6 (PDE6) mutations cause around $4-5 \%$ of the retinitis pigmentosa, a rare form of retinal degeneration. The aim of this study was to evaluate whether pharmacological PDE6 inhibition induced retinal degeneration in cone-enriched cultures of porcine retina similar to that found in murine models. PDE6 inhibition was induced in cone-enriched retinal explants from pigs by Zaprinast. PDE6 inhibition induced cGMP accumulation and triggered retinal degeneration, as determined by TUNEL assay. Western blot analysis and immunostaining indicated that degeneration was accompanied by caspase-3, calpain-2 activation and poly (ADP-ribose) accumulation. Oxidative stress markers, total antioxidant capacity, thiobarbituric acid reactive substances (TBARS) and nitric oxide measurements revealed the presence of oxidative damage. Elevated TNF-alpha and IL-6, as determined by enzyme immunoassay, were also found in cone-enriched retinal explants treated with Zaprinast. Our study suggests that this ex vivo model of retinal degeneration in porcine retina could be an alternative model for therapeutic research into the mechanisms of photoreceptor death in cone-related diseases, thus replacing or reducing animal experiments.
\end{abstract}

(ㄷ) 2013 Published by Elsevier Ltd.

0014-4835/\$ - see front matter (c) 2013 Published by Elsevier Ltd. http://dx.doi.org/10.1016/j.exer.2013.03.015 
conjugated again to opsin to form a new, functional visual pigment. Rods and cones recover from excitation and recover their lightsensitivity by both inactivating the PDE6 cascade and synthetizing new cGMP by $\mathrm{Ca}^{2+}$-sensitive membrane guanylyl cyclases (RetGCs). RetGCs are controlled by a calcium negative feedback through $\mathrm{Ca}^{2+}$ । $\mathrm{Mg}^{2+}$ binding proteins, GCAPs (guanylyl cyclase activating proteins) (Burns et al., 2002; Koch and Stryer, 1988). Alterations in any step of the phototransduction cascade could lead to photoreceptor cell death.

Cyclic GMP is essential for the ability of rods and cones to respond to the light stimuli and the control of its level is critical for proper functioning of photoreceptors. Mutations in genes involved Q2 in cGMP synthesis (RetGCs and GCAPs) or degradation (PDE6) (Chang et al., 2009; Dizhoor, 2000; Grau et al., 2011; Piri et al., 2005; Hunt et al., 2010) can lead to various forms of retinal dystrophies such as some types of retinitis pigmentosa (Bowes et al., 1990; McLaughlin et al., 1993), progressive cone dystrophy (Thiadens et al., 2009), dominant cone degeneration (Behnen et al., 2010; Jiang and Baehr, 2010), cone-rod dystrophy (Buch et al., 2011; Sokal et al., 2005; Tucker et al., 1999) and Leber congenital amaurosis (Perrault et al., 2000, 1996).

Retinitis Pigmentosa (RP) is a common form of rod-cone dystrophy, constituting the largest Mendelian genetic cause of blindness in the developed world. Patients with RP typically loose night vision in adolescence, peripheral vision in young adulthood, and central vision later in life due to progressive loss of rod and cone photoreceptor cells. Photoreceptor cell death starts with rod photoreceptor degeneration and eventually cone cell death that is the major problem affecting RP patients, because it leads to loss of central vision (Kalloniatis and Fletcher, 2004).

Mutations in genes encoding $\alpha$ and $\beta$-subunit of PDE6 have been reported to cause recessive RP in humans (Corton et al., 2010; Dryja et al., 1999; Huang et al., 1995; McLaughlin et al., 1995). PDE6A $^{\text {nmf363/nmf363, PDE6A }}{ }^{\text {nmf282/nmf2823 }}$ (Sakamoto et al., 2009), PDE6B $^{\text {rd1 }}$ and PDE6B ${ }^{\text {rd10 }}$ mice are models of human autosomal recessive RP that carry mutations on the $\alpha$ or the $\beta$-subunit of PDE6 (Bowes et al., 1990; Chang et al., 2002), that triggers photoreceptor degeneration (Farber and Lolley, 1974; Paquet-Durand et al., 2009). Others than the available murine models have been reported to carry mutations in PDE6 subunits such as the canine models rcd1 and rcd2 (Petersen-Jones et al., 1999; Sargan et al., 1994; Suber et al., 1993; Tuntivanich et al., 2008; Wang et al., 1999).

Although murine models provide invaluable information about photoreceptor cell death, they present different eye size and anatomic differences in retinal structures compared to humans; for example, they lack macula and fovea. This is why the use of large animal models seems to be critical for the development of retinal rescue strategies (Stieger et al., 2009). Anatomically, the pig eye is remarkably similar to the human eye and it is well-endowed with cones (Gerke et al., 1995) especially, in a large horizontal band extending across the retina covering the optic disc and horizontal meridian (Hendrickson and Hicks, 2002). This relative abundance of cones makes the porcine eye a good model for therapeutic research into the mechanisms of photoreceptor degeneration in cone-related diseases.

The mechanisms responsible for photoreceptor cell death still remain unclear however, increasing evidence suggests that oxidative stress (Komeima et al., 2006; Shen et al., 2005) and inflammation (de Kozak et al., 1997; Yang et al., 2007; Yoshida et al., 2013a,b) contribute to the pathogenesis of RP. Recently, Yoshida et al. (2013a,b) have been found elevated inflammatory mediators in the eye of $r d 10$ mice and of patients with RP including TNF-alpha.

This study investigated whether PDE6 inhibition produced ex vivo retinal degeneration in cone-enriched cultures of porcine retina similar to the degeneration found in murine models of RP with non-functional PDE6. Secondly, we assessed whether the damage was accompanied with oxidative stress and induction of inflammatory mediators.

We found that PDE6 inhibition triggered retinal degeneration with caspase-3, calpain-2 activation and PAR accumulation (indicator of PARP activity) and induced oxidative stress and cytokine induction in cone-enriched cultures of porcine retina. These results suggest that the cone-enriched organotypic culture of porcine retina exposed to PDE inhibitor could be a complementary model for therapeutic research into the mechanisms of retinal degeneration, thus replacing or reducing animal experiments.

\section{Materials and methods}

\subsection{Porcine retinal explant cultures}

Sixty eyes (both left and right eye) from small miniature pigs $3-$ 7 months old were obtained from the local slaughterhouse. Neuroretina explants enriched in cones were carried out as previously described (Fernandez-Bueno et al., 2008) with some modifications. Briefly, each eyeball was immersed in 70\% ethanol and washed in Dulbecco's Modified Eagle Medium (DMEM). All extraocular tissues were removed and the sclera was punctured with a 22 gauge needle at the ora serrata and bisected, dividing the ocular globe into anterior and posterior eyecups. The vitreous was removed, and the posterior eyecup was placed into a dish with phosphate buffer saline (PBS). A paintbrush was used to mechanically detach the neuroretina from the RPE, and the optic nerve was cut with Westcott scissors. The visual streak with a high cone density (Hendrickson and Hicks, 2002) was cut into $5 \times 5 \mathrm{~mm}$ explants. Explants were transferred to Transwell ${ }^{\circledR}$ culture dishes (Corning Inc., Corning, NY) with photoreceptor side down, containing $1.5 \mathrm{~mL}$ culture medium composed of Neurobasal A medium supplemented with 2\% B-27 (Invitrogen, Life Technologies, Madrid, Spain), 2 mM Lglutamine (Invitrogen, Life Technologies, Madrid, Spain), $100 \mathrm{U} / \mathrm{mL}$ penicillin, and $100 \mathrm{ng} / \mathrm{mL}$ streptomycin (Invitrogen, Life Technologies, Madrid, Spain). Explants were cultured at $37^{\circ} \mathrm{C}$ with $5 \% \mathrm{CO}_{2}$ in a humidified atmosphere. The culture medium level was maintained in contact with the support membrane beneath the explant. Treatments were added the day of the culture and maintained them for $24 \mathrm{~h}$ or $48 \mathrm{~h}$.

To evaluate the effect of PDE6 inhibition we used Zaprinast (Zhang et al., 2005) (100, 200 and $500 \mathrm{nmol} / \mathrm{L}$ ). Zaprinast (SigmaAldrich, Madrid, Spain) was prepared in dimethyl sulfoxide (DMSO) (AppliChem, Darmstadt, Germany). For controls, the same amount of DMSO was added to the culture medium. Some retinal explants were also exposed to $2 \mu \mathrm{mol} / \mathrm{L}$ A231187, a calcium ionophore, as apoptotic inducer (Sigma-Aldrich, Madrid, Spain).

Freshly detached neuroretinas were also obtained for normal morphologic and biochemical evaluation.

\subsection{Tissue processing and histology}

For morphological characterization retinal explants were fixed in $4 \%$ filtered paraformaldehyde (Sigma-Aldrich, Madrid, Spain) and 2.5\% glutaraldehyde (Electron Microscopy Sciences, Hatfield, UK) in $0.1 \mathrm{M}$ PBS (pH 7.4) for $2 \mathrm{~h}$. Afterwards explants were post-fixed with $2 \%$ osmium tetroxide, rinsed, dehydrated and embedded in Durcupan resin (Fluka, Sigma-Aldrich, Madrid, Spain). Semi-thin sections were cut at $1.5 \mu \mathrm{m}$, mounted on gelatincoated slides and stained with $1 \%$ toluidine blue. These sections were examined under an Eclipse 80i microscope (NIKON Instruments, Badhoevedorp, The Netherlands) and images were captured with a DS-Qi1 digital camera (NIKON Instruments, 
Badhoevedorp, The Netherlands). Image software was used to quantify the thickness of the retinal explants. After calibration, total area of at least three visual fields per retinal explant was calculated. The total area was expressed as $\mu \mathrm{m}^{2}$. Data are expressed as mean \pm SEM.

To evaluate apoptosis with the terminal deoxynucleotidil transferase dUTP nick and labeling (TUNEL) assay, retinal explants were fixed in $4 \%$ filtered paraformaldehyde (Sigma-Aldrich, Madrid, Spain) in 0.1 M PBS (pH 7.4) and cryoprotected in a saccharose gradient (15-20-30\%) (Panreac Química, Barcelona, Spain). Samples were frozen embedded in Tissue-Tek ${ }^{\circledR}$ O.C.T. ${ }^{\text {TM }}$ Compound (Sakura Finetek Europe B.V., Zoeterwoude, The Netherlands). Next, $10 \mu \mathrm{m}$ sections were cut with a cryostat (Leica CM1900, Nussloch, Germany) and placed on Super Frost Ultra Plus treated slides (Thermo Scientific, Barcelona, Spain).

\subsection{TUNEL assay}

The TUNEL assay was performed on $10 \mu \mathrm{m}$ cryosections by means of an in situ cell death detection kit conjugated with rhodamine fluorochrome (ApopTag Red In Situ) (Millipore, Schwalbach, Germany) according to the manufacturer's instructions. The specimens were examined under a Eclipse 80i microscope (NIKON Instruments, Badhoevedorp, The Netherlands) and images were captured with a DS-Qi1 digital camera (NIKON Instruments, Badhoevedorp, The Netherlands). The apoptotic (TUNEL-positive) nuclei per visual field were counted in at least three visual fields per each retinal explant using NIS-Elements imaging software (NIKON Instruments, Badhoevedorp, The Netherlands). The data were analysed quantitatively and, only cells with red intensity were considered TUNEL-positive. The number of apoptotic nuclei was normalised to the SYTOX Green-labelled cell nuclei. Results are given as percentage of apoptotic nuclei/total nuclei. Data are expressed as mean $\pm \mathrm{SEM}$.

\subsection{Immunofluorescence of Caspase-3 and PAR}

Immunofluorescence was carried out on $10 \mu \mathrm{m}$ cryosections. Sections were post-fixed for $15 \mathrm{~min}$ at room temperature in $4 \%$ filtered paraformaldehyde (Sigma-Aldrich, Madrid, Spain) in $0.1 \mathrm{M}$ PBS ( $\mathrm{pH}$ 7.4). Sections were incubated for $1 \mathrm{~h}$ in blocking solution containing $5 \%$ normal goat serum, $1 \%$ bovine serum albumin and $0.25 \%$ Triton X-100. They were then incubated with primary antibody against cleaved Caspase-3 (1:200, Cell Signaling Technology, Barcelona, Spain) or PAR (poly-(ADP-ribose) (1:200, Enzo Life Sicence, Madrid, Spain) overnight at $4{ }^{\circ} \mathrm{C}$ in blocking solution. After washing with PBS three times, samples were incubated for $1 \mathrm{~h}$ at room temperature with the fluorescenceconjugated secondary antibody Alexa Fluor 647 (Invitrogen, Life Technologies, Madrid, Spain). After washing with PBS three times, sections observed under a confocal microscope (Leica TCS SP5 Confocal microscope, Leica Microsistemas S.L.U, Barcelona, Spain). SYTOX Green (Molecular Probes, Paisley, UK) were used as a specific nuclear counterstain. Cells were counted $40 \times$ magnification, and the number of caspase- 3 positive cells was counted manually in four visual fields per each retinal explant. The number of cells positive for the cleaved caspase- 3 immunolabelling was normalised to the SYTOX Green-labelled cell nuclei. Results are given as percentage of caspase-3 positive cell/total nuclei. Data are expressed as mean \pm SEM.

PAR positive cells were difficult to count in outer nuclear layer (ONL). For the quantification of PAR immunostaining we used the following formula to calculate the corrected fluorescence (CF) for each cell layer: $\mathrm{CF}=$ Integrated density of the selected area - (area of selected area $\times$ mean fluorescence of background) (Burgess et al., 2010). Data are expressed as mean \pm SEM.

For co-localization with cleaved caspase-3 or PAR, staining was followed by TUNEL staining.

\subsection{Cyclic GMP determination}

cGMP was measured by using the BIOTRAK cGMP enzyme immunoassay kit (GE Healthcare Europe GmbH, Barcelona, Spain). Retinal explants were homogenised in 5\% trichloroacetic acid and neutralized with $2 \mathrm{M}$ potassium bicarbonate. Neutralized supernatant was used for cGMP determination. Protein content was measured by the bicinchoninic acid (BCA) protein assay (BCA Kit; Pierce Scientific, CA). The tissue cGMP levels were expressed as $\mathrm{pmol} / \mathrm{mg}$ protein.

\subsection{Caspase-3 activity assay}

Caspase-3 activity was measured with a colorimetric tetrapeptide (DEVD-pNA) cleavage assay kit following the manufacturer's instructions (Bio-Vision, Mountain View, CA). Total retinal protein was extracted from retinal explants and measured by the BCA protein assay. Caspase-3 activity was expressed as arbitrary units (au)/mg of protein.

\subsection{Nitrites and nitrates (NOX) determination}

Intracellular and extracellular nitrites (stable end-product of NO) and nitrates (NOX) were measured in retinal explants by spectrophotometric GRIESS reaction (El-Mlili et al., 2008) using nitrate reductase. The tissue NOX levels were expressed as nmol/ $\mathrm{mg}$ protein (intracellular) or $\mathrm{nmol} / \mathrm{mL}$ (extracellular).

\subsection{Oxidative stress evaluation}

Retinal explants were assayed for total antioxidant capacity (TAC) and thiobarbituric acid reactive substances (TBARS) formation as indicator of malonyldialdehyde (MDA) formation.

Retinal explants were homogenized in $5 \mathrm{mM}$ phosphate buffer $\mathrm{pH} 7,0.9 \% \mathrm{NaCl}, 0.1 \%$ glucose, centrifuged at $10,000 \times \mathrm{g}$ for $15 \mathrm{~min}$ at $4{ }^{\circ} \mathrm{C}$, and then the supernatants were used to determine TAC and TBARS. Protein concentrations were measured by the BCA protein assay.

TAC was measured using a commercial kit (Cayman Chemical, Ann Arbor, MI) (Kowluru et al., 2006). The tissue TAC levels were expressed as $\mathrm{nmol} / \mathrm{mg}$ protein.

MDA levels were detected by a colorimetric method involving thiobarbituric acid (TBA) adduct formation (Cayman Chemical, Ann Arbor, MI). Tissue TBARS levels were expressed as $\mathrm{nmol} / \mathrm{mg}$ protein.

\subsection{TNF-alpha and IL-6 measurement}

For detection of cytokine levels, retinal explants were homogenized in $20 \mathrm{mM}$ Tris- $\mathrm{HCl}$ pH 7.4, 10 mM EDTA containing protease inhibitor cocktail (Complete Protease Inhibitor Cocktail; Roche, Basel, Switzerland) and $200 \mu \mathrm{M}$ phenylmethylsufloxifluoride (PMSF). The TNF- $\alpha$ and IL- 6 protein levels were estimated with the corresponding ELISA kit (Diaclone, Besancon, France), according to the manufacturers' instructions. Tissue cytokine levels were expressed as $\mathrm{pg} / \mathrm{mg}$ protein.

Values for cGMP, caspase-3 activity, NOX, oxidative markers and cytokines are given as the mean \pm SEM of at least ten different cultures. For each experiment samples were measured in duplicate. 


\subsection{Western blot}

Retinal explants were homogenized in lysis buffer (50 mM Tris$\mathrm{HCl}$ buffer pH 7.4 containing $50 \mathrm{mM} \mathrm{NaCl}, 5 \mathrm{mM}$ EDTA, 1\% SDS, protease inhibitor cocktail (Complete Protease Inhibitor Cocktail; Roche, Basel, Switzerland) and $1 \mathrm{mM}$ PMSF). Samples (30 $\mu \mathrm{g}$ ) were subjected to electrophoresis and immunoblotting as described in Corbalán et al. (2002). The following primary antibodies were used: cleaved caspase-3 (Asp175) rabbit polyclonal antibody (1:1000, Cell Signaling Technology, Danvers, MA, USA), calpain-2 rabbit polyclonal antibody (1:1000; Sigma-Aldrich, Madrid, Spain); and $\beta$-actin mouse monoclonal antibody (1:2000; Sigma-Aldrich, Madrid, Spain). The images were captured using an EPSON SCAN from EPSON Corporation (EPSON IBERICA, Barcelona, Spain) and quantified using the Alpha Imager 2200 (version 3.1.2) software (AlphaInnotech Corporation, San Francisco, CA, USA).

\subsection{Statistical analyses}

For parametric data, ANOVA followed by Newman-Keul's posthoc test was used. When only two samples were compared the Student's $t$-test was used.

For non-parametric data, Mann-Whitney test was used. Significance levels were set at $\alpha=0.05$.

\section{Results}

\subsection{PDE inhibition triggers CGMP accumulation in cultured porcine retina}

Retinal explants were cultured for $48 \mathrm{~h}$ in the presence or absence of Zaprinast, a selective PDE5/6 inhibitor which raises intracellular cGMP levels in a concentration-dependent manner and causes cGMP-dependent photoreceptor degeneration in small animals closely resembling the $r d 1$ degeneration (Sahaboglu et al., 2010).

Successful PDE6 inhibition was confirmed by a significant cGMP increase at all time points evaluated (Fig. 1). While untreated retina essentially maintained the same level of cGMP, the Zaprinasttreated retina showed a strong increase of cGMP accumulation at $24 \mathrm{~h}$ in a dose-dependent manner $(1.72 \pm 0.3 ; 2.04 \pm 0.2$, $2.78 \pm 0.27 \mathrm{pmol} / \mathrm{mg}$ protein at 100,200 and $500 \mathrm{nmol} / \mathrm{L}$ respectively, One-way ANOVA post-hoc Newman-Keuls $p<0.05$ ). Under our experimental conditions, the effect of Zaprinast concentration on cGMP accumulation disappeared at $48 \mathrm{~h}$.

$100 \mathrm{nmol} / \mathrm{L}$ Zaprinast was the lowest concentration that induced a significant cGMP accumulation at $24 \mathrm{~h}$ and $48 \mathrm{~h}$. In view

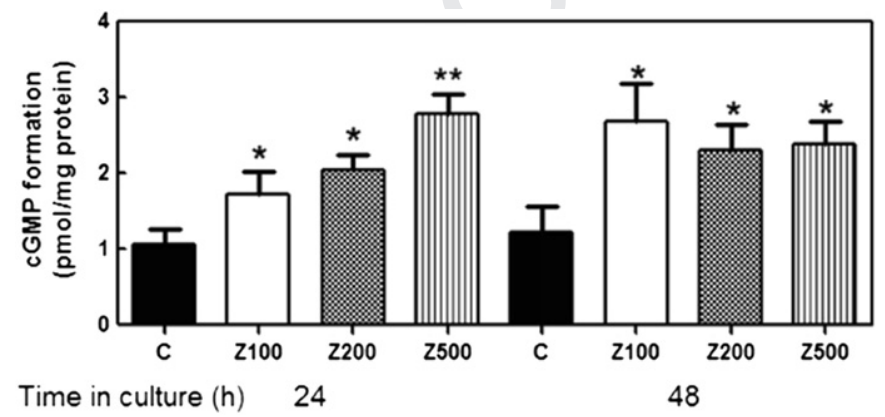

Fig. 1. PDE6 inhibition induces cGMP accumulation in cone-enriched cultures of porcine neuroretina. Control retinal explants (C) or explants treated with 100 (Z100), 200 (Z200) or 500 (Z500) nmol/L Zaprinast were prepared as described in Materials and methods. The levels of cGMP at different times in culture are shown. Values are the mean \pm SEM of twelve cultures. Values significantly different from own control are indicated by asterisks ${ }^{*} p<0.05,{ }^{* *} p<0.01$ (ANOVA Newman-Keuls post-hoc). of these results, $100 \mathrm{nmol} / \mathrm{L}$ seemed to be the best concentration of Zaprinast for further studies.

\subsection{Evaluation of organotypic retina cultures}

Toluidine blue staining of semi-thin sections demonstrated that the overall architecture of the cultured retina was maintained throughout the culture period (Fig. 2A). However, morphometric analysis revealed that explants treated with $100 \mathrm{nmol} / \mathrm{L}$ Zaprinast were significantly thinner $\left(47,915 \pm 2938 \mu \mathrm{m}^{2}\right.$, Mann-Whitney test, $p<0.01$ and 33,129 $\pm 1365 \mu \mathrm{m}^{2}$, Mann-Whitney test, $p<0.05)$, compared with controls $\left(58,940 \pm 861 \mu \mathrm{m}^{2}\right.$ and $42,000 \pm 2220 \mu \mathrm{m}^{2}$ ) at $24 \mathrm{~h}$ and $48 \mathrm{~h}$ respectively (Fig. 2B). Zaprinast also decreased photoreceptor outer segments (OS) compared to control explants (Fig. 2A).

\subsection{PDE inhibition induces apoptosis in cultured porcine retina}

The TUNEL assay was performed to measure the apoptotic cell death in fresh isolated retinas, control explants and explants treated with different Zaprinast concentrations (Fig. 3). While fresh isolated retina did not present any apoptotic nuclei, control explants showed a few apoptotic nuclei $(2.4 \pm 0.7 \%$ of TUNEL-positive cells) after $24 \mathrm{~h}$ in culture.

TUNEL staining demonstrated that inhibition of PDE induced photoreceptor degeneration overall after $48 \mathrm{~h}$ of Zaprinast treatment. As shown in Fig. 3A and Table 1, apoptotic nuclei were found in outer nuclear layer (ONL), in inner nuclear layer (INL) and also in the ganglionar layer (GCL) at the lower dose of Zaprinast (100 nmol/ L). The major effect was observed in ONL ( $4.6 \pm 1.3 \%$ of apoptotic cells, Mann-Whitney test, $p<0.0001)$. Moreover, Zaprinast caused significant increase of TUNEL-positive cells (ANOVA test, post-hoc Newman-Keuls, $p<0.05$ ) after $24 \mathrm{~h}$ in a concentrationdependent manner (Fig. 3B).

As shown in Fig. 3 control explants showed low numbers of TUNEL-positive cells after $24 \mathrm{~h}$ in culture $(2.4 \pm 0.7 \%$ of apoptotic cells) but, this number increased across the whole retinal explant (ONL, INL and GCL) after $48 \mathrm{~h}(6.7 \pm 1.0 \%$ of apoptotic cells). This cell death was consequence of retinal detachment and culturing time.

To further investigate the impact of PDE inhibition on downstream effectors of cell death, we analysed the activity of caspase-3, and activation of calpain-2.

After $24 \mathrm{~h}$, caspase-3 activity (Fig. 4A) and protein content of cleaved caspase-3 (Fig. 4B) were further up regulated in retina treated with $100 \mathrm{nmol} / \mathrm{L}$ Zaprinast $(2.4 \pm 0.1 \mathrm{au} / \mathrm{mg}$ protein and $2.1 \pm 0.4$ fold over control retina respectively, student $t$-test, $p<0.05)$. This up regulation was maintained at $48 \mathrm{~h}(2.4 \pm 0.2 \mathrm{au} /$ mg protein and $2.7 \pm 0.8$ fold over control retina, student $t$ test, $p<0.05)$. Immunofluorescence of cleaved caspase-3 revealed that PDE inhibition significantly up regulated caspase-3 in INL ( $2.6 \pm 0.3 \%$ of caspase -3 positive cells, $p<0.0005)$ and GCL $(1.7 \pm 0.2 \%$ of caspase- 3 positive cells, $p<0.01)$ but not in ONL ( $0.3 \pm 0.1 \%$ of caspase -3 positive cells), after $24 \mathrm{~h}$ in culture (Table 1 and Fig. 4C). Control explants also showed up regulation of caspase3 mainly in GCL after $48 \mathrm{~h}$.

Western blot analysis showed that PDE6 inhibition also induced calpain-2 activation (Fig. 4D). A Ca $^{2+}$ ionophore, A231187, was used to confirm calpain-2 activation.

Strong activation of poly(ADP-ribose) polymerase (PARP) has been found in animal models of retinal degeneration with subsequent accumulation of poly(ADP-ribose) (PAR) polymers (PaquetDurand et al., 2007; Kaur et al., 2011). Excessive PARP activation may contribute to caspase-independent photoreceptor death (Paquet-Durand et al., 2007; Kaur et al., 2011). To investigate indirectly PARP activity in Zaprinast-treated explants, we 


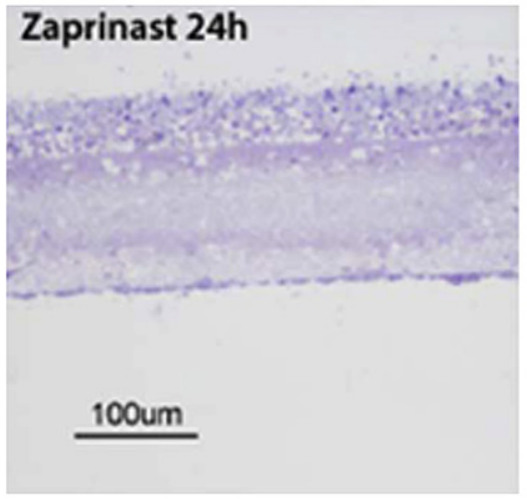

Control 48h
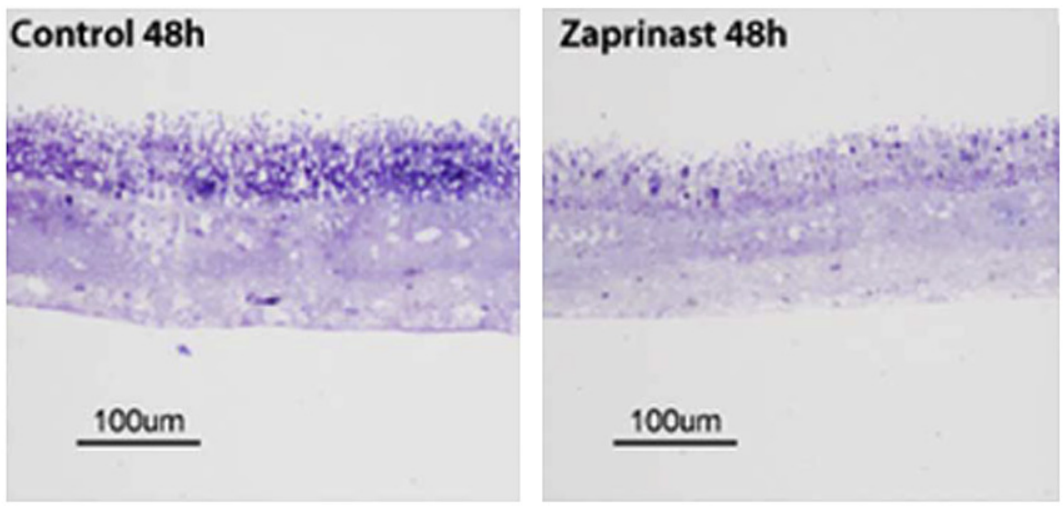

B

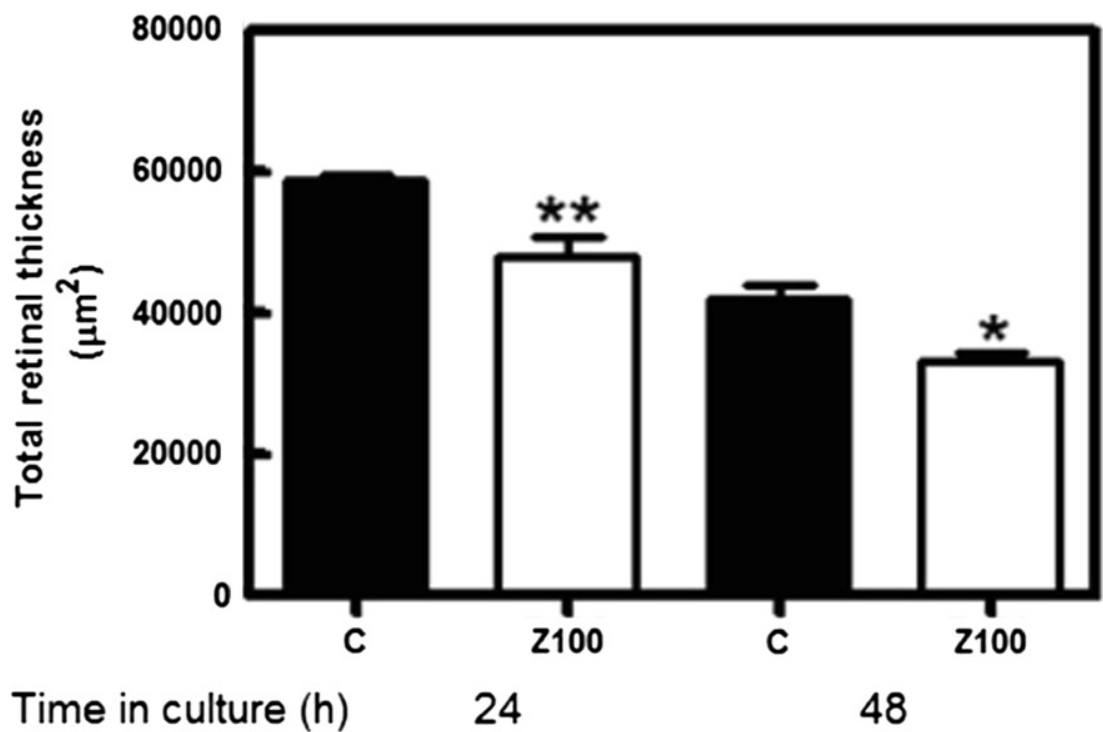

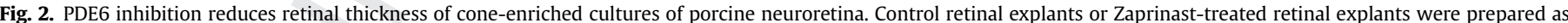

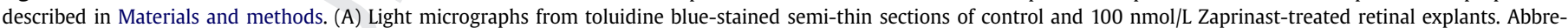

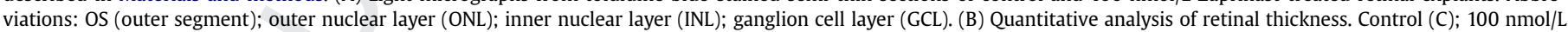

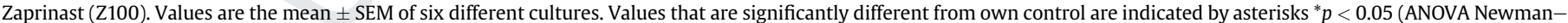
Keuls post-hoc).

performed PAR immunostaining. PDE6 inhibition significantly increased accumulation of poly(ADP-ribosyl)ated proteins in ONL $(23,744 \pm 5304$ corrected fluorescence, Mann-Whitney test, $p<0.05)$ compared to control (7497 \pm 722 corrected fluorescence) after $24 \mathrm{~h}$ in culture (Table 1).

To determine whether cleaved caspase-3 or PAR co-localize with TUNEL-positive cells, we performed double labelling (Fig. 5). In Zaprinast-treated explants PAR immunostaining co-localized to a large extent with TUNEL-positive cells in GCL and ONL. A few number of cells in INL also co-localized with PAR. However, caspase3 positive cells did not co-localize with TUNEL-positive cells except for a subset of cells in INL. Moreover, double-immunostaining of caspase-3 and PAR reflected co-localization in a subset of cells in GCL and INL. Caspase-3 activation occurs mainly in INL and it may partially contribute to cell death in this cell layer. Moreover, caspase3 activation also occurs in GCL and could contribute to the future cell 

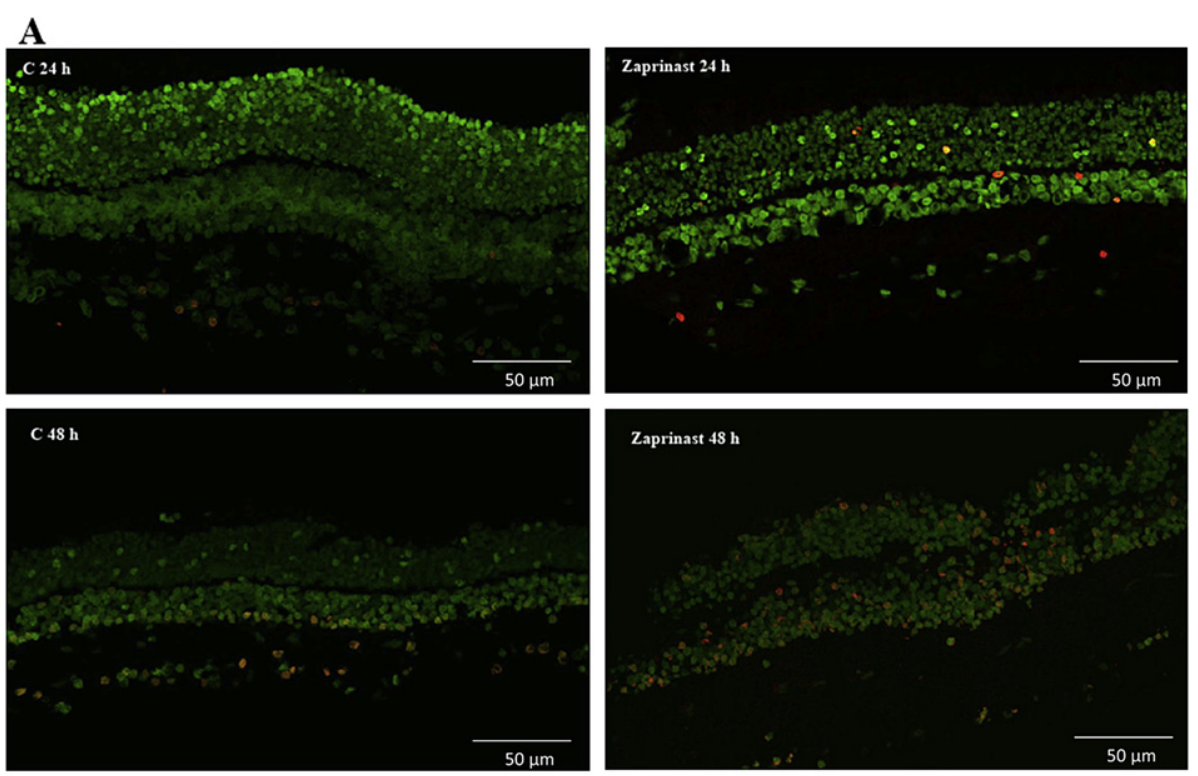

B

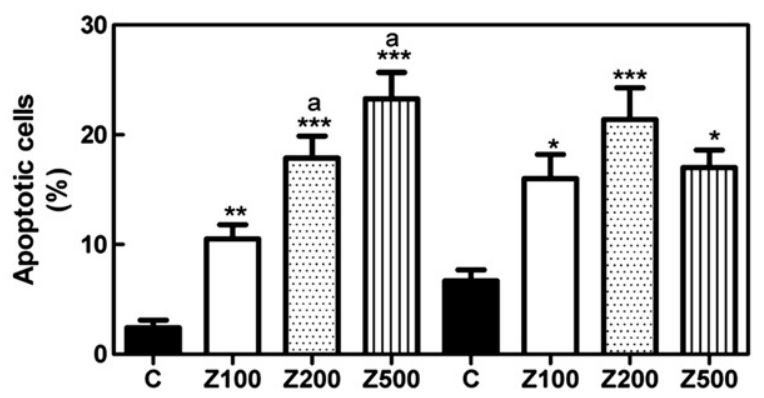

Time in culture (h)

24

48

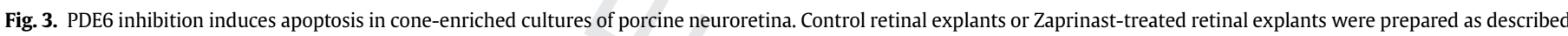

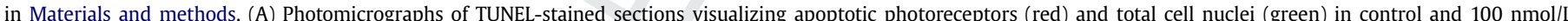

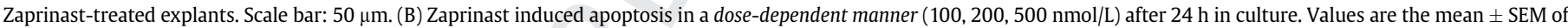

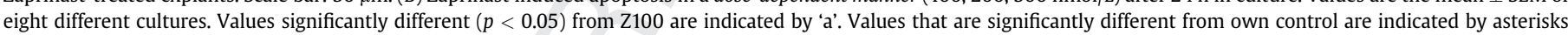
${ }^{*} p<0.05$ (ANOVA Newman-Keuls post-hoc). (For interpretation of the references to color in this figure legend, the reader is referred to the web version of this article.)

death. Taking together, these results suggest that PDE6 inhibition probably induces cell death by caspase-independent mechanisms (PARP activity) in ONL and GCL and by caspase-dependent and caspase-independent mechanisms in INL.

\subsection{PDE inhibition induces oxidative stress and cytokine production in cultured porcine retina}

It has been described that cGMP accumulation induces oxidative stress in murine models of retinal degeneration (Sharma and Rohrer, 2007). To explore whether PDE inhibition also induced oxidative damage in cultured porcine retina we measured: intracellular and extracellular nitrites formation (iNOX and eNOX) as measurement of nitric oxide, TBARS formation as indicator of lipid peroxidation and total antioxidant capacity (Fig. 6).

At $24 \mathrm{~h}$, PDE6 inhibition enhanced iNOX levels compared with control ( $48 \pm 4 \mathrm{nmol} / \mathrm{mg}$ protein and $30 \pm 2 \mathrm{nmol} / \mathrm{mg}$ protein, respectively, student $t$-test, $p<0.05)$. As culturing time moved forward eNOX level also increased compared to control ( $47 \pm 3 \mathrm{nmol} /$ $\mathrm{mL}$ and $36 \pm 2 \mathrm{nmol} / \mathrm{mL}$, respectively, student $t$-test, $p<0.05$ ) (Fig. 6A).

MDA concentration was determined by the thiobarbituric acid (TBA) assay, which measures the amount of TBA reactivity with MDA formed during the acid hydrolysis of lipid peroxide compound. Addition of $100 \mathrm{nmol} / \mathrm{L}$ Zaprinast caused a rapid increase of lipid peroxide TBA value compared with control at $24 \mathrm{~h}$

Table 1

Effect of Zaprinast on cell death markers in porcine retinal explants.

\begin{tabular}{|c|c|c|c|c|c|c|}
\hline \multirow[t]{2}{*}{ Layer } & \multicolumn{2}{|c|}{ TUNEL-positive cells (\%) } & \multicolumn{2}{|c|}{ Caspase-3 positive cells (\%) } & \multicolumn{2}{|c|}{ PAR content (CF) } \\
\hline & $\mathrm{C}$ & Z100 & $\mathrm{C}$ & Z100 & C & Z100 \\
\hline ONL & $0.43 \pm 0.13$ & $4.55 \pm 1.3^{* * *}$ & $0.08 \pm 0.03$ & $0.28 \pm 0.06$ & $7497 \pm 722$ & $23,744 \pm 5304^{*}$ \\
\hline INL & $0.92 \pm 0.20$ & $2.40 \pm 0.40^{* *}$ & $0.29 \pm 0.09$ & $2.64 \pm 0.34^{* * *}$ & $7019 \pm 1163$ & $9640 \pm 2380$ \\
\hline GCL & $0.71 \pm 0.15$ & $2.66 \pm 0.44^{* *}$ & $0.82 \pm 0.27$ & $1.72 \pm 0.24^{* *}$ & $9891 \pm 2011$ & $10,413 \pm 2301$ \\
\hline
\end{tabular}

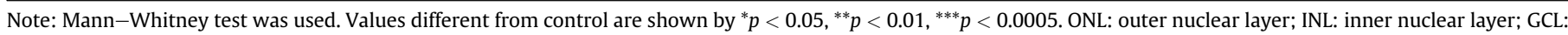
ganglionar nuclear layer; C: control; Z100: 100 nM Zaprinast; CF: corrected fluorescence. 


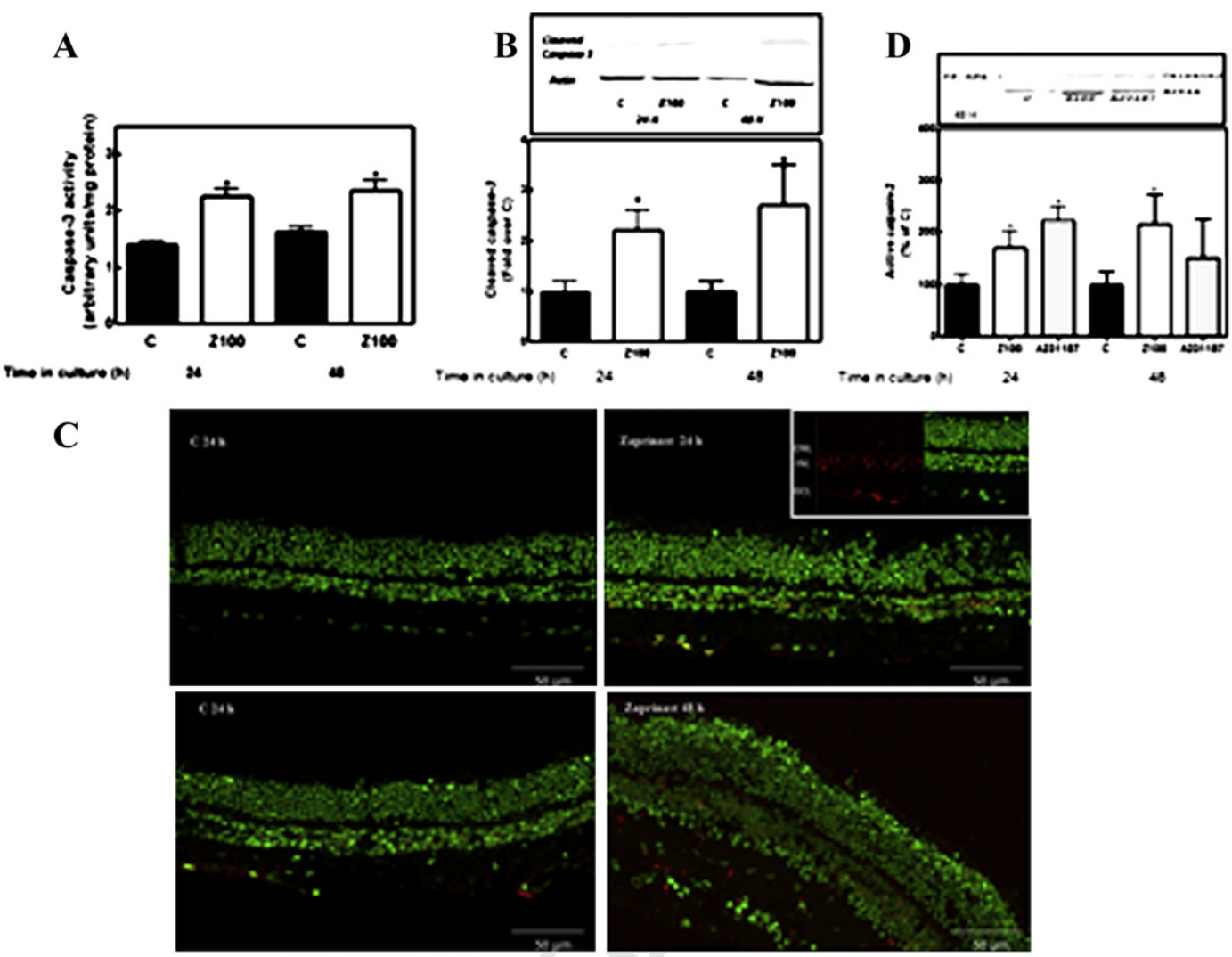

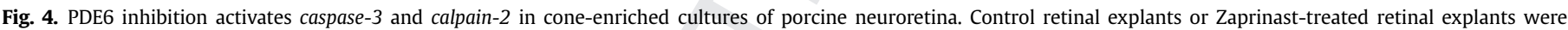

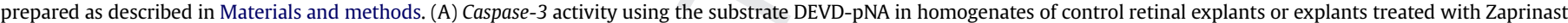

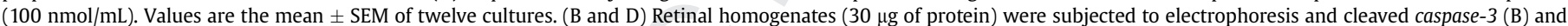

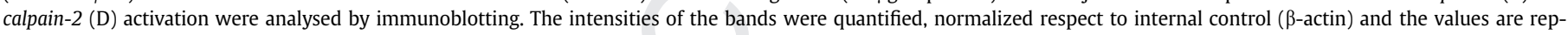

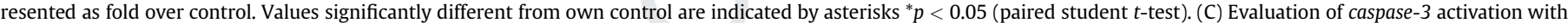
cleaved caspase-3 staining in frozen sections; scale bar, $50 \mu \mathrm{m}$.

$(3.9 \pm 0.4 \mathrm{nmol} / \mathrm{mg}$ protein and $2.0 \pm 0.2 \mathrm{nmol} / \mathrm{mg}$ protein, student $t$-test, $p<0.05)$, remaining elevated at $48 \mathrm{~h}(4.8 \pm 0.5 \mathrm{nmol} / \mathrm{mg}$ protein, student $t$-test, $p<0.05$ (Fig. 6B).

The overall antioxidant capacity of retinal explants treated with $100 \mathrm{nmol} / \mathrm{L}$ Zaprinast, decreased at $24 \mathrm{~h}$ and $48 \mathrm{~h}(174 \pm 12 \mu \mathrm{mol} / \mathrm{mg}$ protein and $156 \pm 9 \mu \mathrm{mol} / \mathrm{mg}$ protein respectively, student $t$-test, $p<0.05)$, compared to control retinal explants $(225 \pm 21 \mu \mathrm{mol} / \mathrm{mg}$ protein and $192 \pm 14 \mu \mathrm{mol} / \mathrm{mg}$ protein, respectively) (Fig. 6B).

TNF $\alpha$ and IL-6 are upregulated in several inflammatory ocular diseases, including Adamantiades-Behcet disease (Durrani et al., 2007), retinal vascular tumours (Japiassú et al., 2008), neovascular age-related macular degeneration (Seddon et al., 2005), uveitis (Murray et al., 1990), and retinitis pigmentosa (Yoshida et al., 2013a,b). We assessed whether $100 \mathrm{nmol} / \mathrm{L}$ Zaprinast induced these pro-inflammatory mediators in porcine retinal explants (Fig. 6C).

PDE inhibition induced a significant long-lasting upregulation of TNF-alpha at $24 \mathrm{~h}$ and $48 \mathrm{~h}(49.6 \pm 10.2 \mathrm{pg} / \mathrm{mg}$ protein and $50.8 \pm 5.6 \mathrm{pg} / \mathrm{mg}$ protein, respectively, student $t$-test, $p<0.05$ ) compared to control $(26.6 \pm 3.6 \mathrm{pg} / \mathrm{mg}$ protein and $24.5 \pm 2.9 \mathrm{pg} /$ mg protein, respectively).

At $24 \mathrm{~h}$ PDE inhibition also produced IL-6 up regulation $(6.5 \pm 1.8 \mathrm{pg} / \mathrm{mg}$ protein, student $t$-test, $p<0.05)$ compared to control (3.1 $\pm 0.4 \mathrm{pg} / \mathrm{mg}$ protein).

\section{Discussion}

Mutations in genes related to cGMP metabolism as RetGC, GCAPs or PDE6 are involved in several retinal dystrophies including retinitis pigmentosa. Between 4 and $5 \%$ of patients with retinitis pigmentosa present PDE6 mutations leading to non-functional enzyme.

There is a lot of interest in using the pig as a model of retinal disease and stem cell transplantation therapy due to its resemblance to human retina. However, transgenic pigs are expensive and difficult to manage. Porcine organotypic culture of the retina is a choice that could allow us to evaluate the effect of new therapeutic drugs on some retinal changes faster and cheaper than in vivo and has the additional advantage of reducing animal experiments. These organotypic cultures were originally developed to follow cellular and cytoskeletal changes during the culture period (Allamby et al., 1997; Winkler et al., 2002) and more recently to study retinal detachment (Fernandez-Bueno, 2008; Fisher and Lewis, 2003). Here we evaluated whether PDE6 inhibition produced retinal degeneration in enriched-cone cultures of porcine retina.

Firstly, we assessed whether this porcine model reproduces the retinal degeneration observed in small animals after PDE inhibition. Our results showed that PDE inhibition induced cGMP accumulation accompanied by retinal degeneration. These results corroborated those found in small animals both in vivo and in vitro (Sahaboglu et al., 2010; Vallazza-Deschamps et al., 2005). Sahaboglu et al. (2010) demonstrated that Zaprinast caused cGMPdependent photoreceptor degeneration closely resembling the $r d 1$ degeneration observed in murine retinal explants. In the $r d 1$ mouse the high levels of cGMP increase the number of the cGMP-gated channels in the open state, thus allowing intracellular calcium 

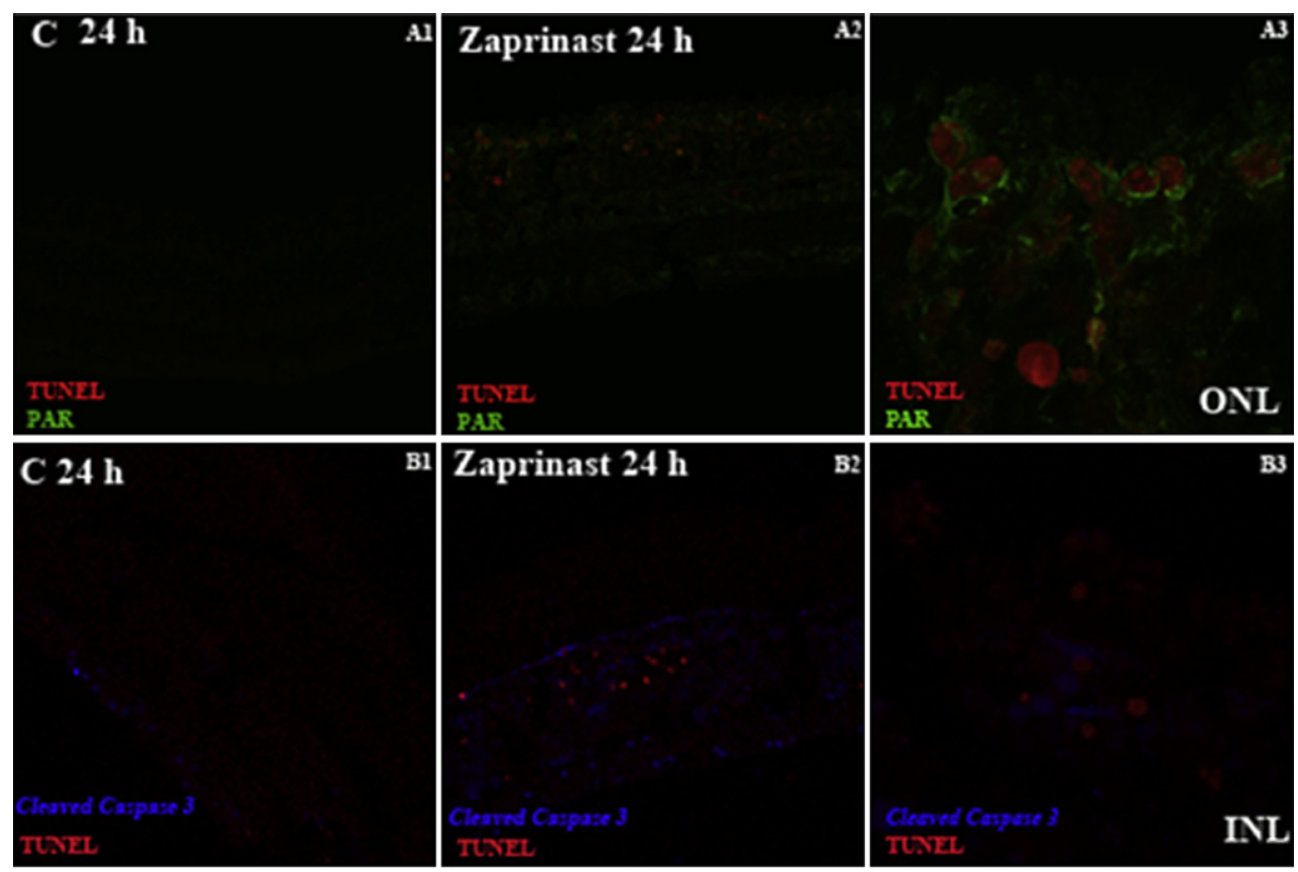

(1)
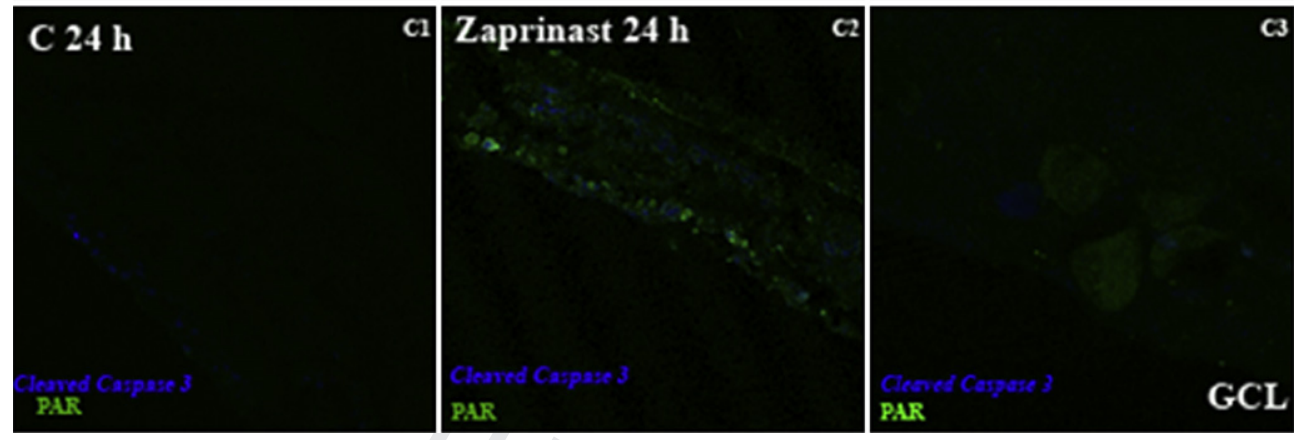

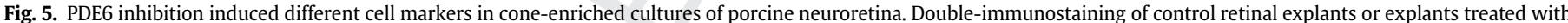

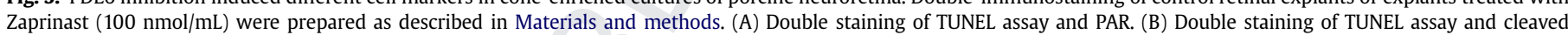

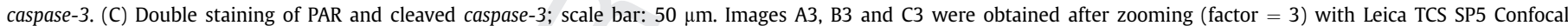
microscope.

$\left(\mathrm{Ca}^{2+}\right)$ to rise to toxic levels and leading to rapid photoreceptor degeneration (Fox et al., 1999). Several studies have pursued to reverse the effects of PDE6 loss function by blocking cGMPgate channel (Vallazza-Deschamps et al., 2005), $\mathrm{Ca}^{2+}$ channel (Nakazawa, 2011) or PKG activity (Paquet-Durand et al., 2009). All these treatments reduced photoreceptor cell death.

We reported that sustained elevation of intracellular cGMP in porcine retinal explants triggered different downstream effectors of cell death related to caspase-dependent mechanisms (caspase-3) and caspase-independent mechanisms (calpain-2 and probably PARP activity, measured as PAR accumulation). In 661W cells inhibition of PDE, increases the intracellular $\mathrm{Ca}^{2+}$ that in turns activates the cysteine protease calpain, which executes apoptosis via modulation of caspase-3 activity (Sharma and Rohrer, 2004). Caspase activation occurs mainly through the extrinsic and intrinsic pathways (Bredesen et al., 2006). Although caspase-3 inhibitors have been transiently effective in delaying retinal degeneration through inhibition of the apoptosis of photoreceptor cells in $r d$ gene-carrying mice (Yoshizawa et al., 2002), the role of caspases in inherited retinal degeneration is controversial (Doonan et al., 2003; Sanges et al., 2006; Zeiss et al., 2004). Recent studies have shown that several caspase-independent inducers of cell death such as AIF (apoptosis-inducing factor), calpains, PARP are activated during retinal degeneration (Kaur et al., 2011; Paquet-Durand et al., 2010; Sanges et al., 2006). In our model caspase-3 activation seems to be involved in part of cell death in INL but neither in GCL nor ONL. However, co-localization of PAR accumulation with TUNEL-positive cells suggests that caspase-independent mechanisms are involved in cell death in ONL and GCL. It is important to highlight that although TUNEL is used as an apoptotic marker, it also can detect non-apoptotic DNA fragmentation, e.g. in necrosis (Grasl-Kraupp et al., 1995). Taken together, these findings suggest the involvement of multiple death signalling mechanisms (caspase-dependent and caspase-independent mechanisms) in retinal cell death after PDE6 inhibition in porcine retina.

We have described that PDE inhibition induced the inflammatory mediators TNF-alpha and IL-6 in porcine retina. Elevated levels of these two inflammatory mediators have been recently described in the eye of patients with RP and $r d 10$ mice (Yoshida et al., 2013a,b). TNF-alpha or IL- 6 have been also observed in other eye diseases, including uveitis, proliferative vitreoretinopathy, retinal detachment and age-related macular degeneration (El-Ghrably et al., 1999; Klein et al., 2008; Nakazawa et al., 2011). TNF- $\alpha$ is likely secreted from activated macrophages, astrocytes, microglial cells and retinal Müller glial cells. It has been described that TNF-alpha has cytotoxic effects on photoreceptors (Nakazawa et al., 2006, 2011). TNF-alpha 
A

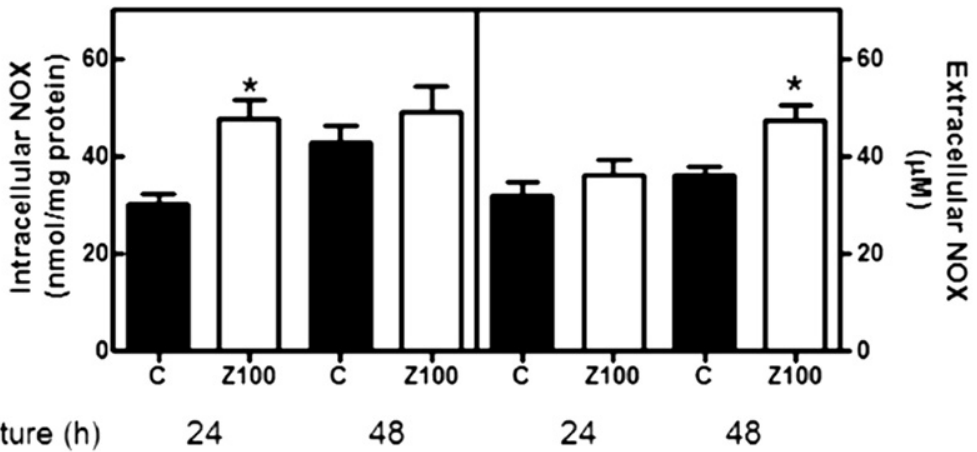

B

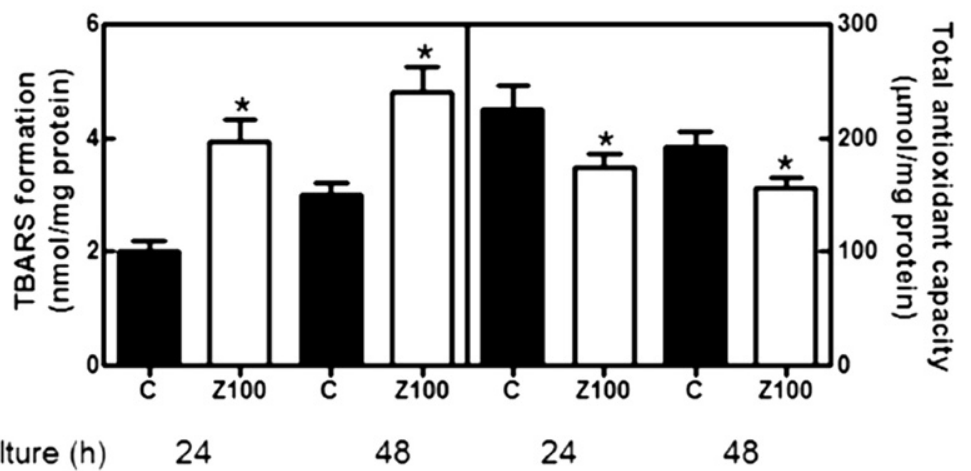

C

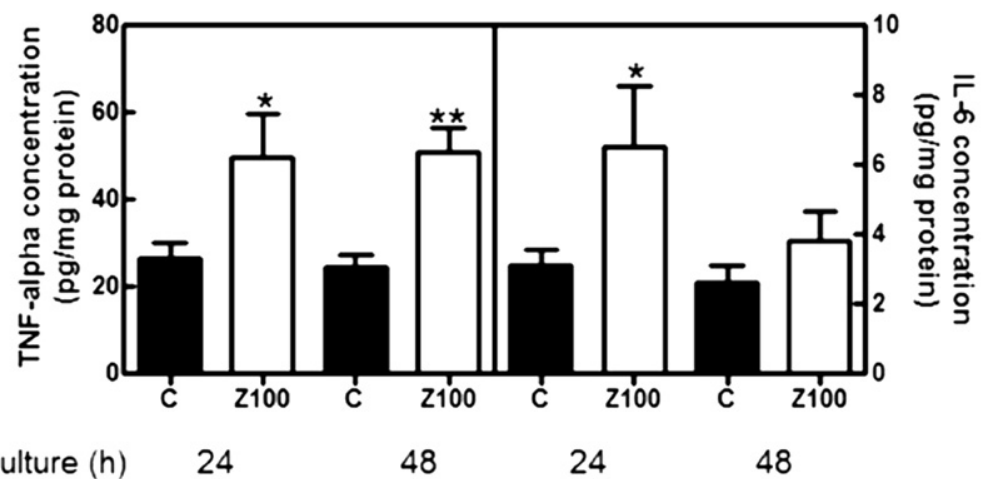

Fig. 6. PDE inhibition triggers oxidative stress and cytokine production cone-enriched cultures of porcine neuroretina. Control retinal explants or explants treated with Zaprinast $(100 \mathrm{nmol} / \mathrm{mL}$ ) were prepared as described in Materials and methods. (A) Effect of Zaprinast on nitric oxide formation (measurement of nitrites and nitrates (NOX)). Intracellular (iNOX) and extracellular nitrites and nitrates (eNOX) were measured by Griess reaction. (B) Effect of Zaprinast on the total antioxidant capacity and malonyldialdehyde formation (TBARS formation). (C) Effect of Zaprinast on TNF-alpha and IL-6 content. Each sample was measured in duplicate, and the values are the mean \pm SEM of twelve cultures. Values significantly different from own control are indicated by asterisks ${ }^{*} p<0.05,{ }^{* *} p<0.01$ (paired student $t$-test).

can trigger several well-characterized death-promoting (caspasedependent and caspase-independent cell death) and survivalpromoting pathways, depending upon the predominating signalling pathway in the particular cell type (Maianski et al., 2003). TNFalpha binding to cell surface receptors such as TNF receptor 1 mediates activation of initiator caspases (caspase-8, caspase-10), and finally triggers cleavage of effector caspases (extrinsic pathway of cell death) (Nagata, 1997). TNF-alpha binding to cell surface receptors may also elicit anti-apoptotic responses mediated by the activation of the NF- $\kappa$ B pathway.

Several evidence shows that TNF-alpha is also involved in the intrinsic pathway of cell death that is initiated by cellular and DNA damage and particularly employs mitochondria. TNF-alpha and other stimuli can reduce the mitochondrial transmembrane potential resulting in release of mitochondrial factors such as cytochrome c or AIF. AIF rapidly translocates from mitochondria to the nucleus and induces nuclear fragmentation and cell death by autophagic degeneration (Suo et al., 2010; Munemasa et al., 2010; Tezel and Yang, 2004; Lorenzo et al., 1999; Daugas et al., 2000). The translocation of AIF has been implicated in several types of neuronal death, including photoreceptor and ganglion cell death (Hisatomi et al., 2001; Mizukoshi et al., 2010; Thapa et al., 2012; Sanges et al., 2006). Inhibition of nuclear AIF translocation delays retinal degeneration of RCS rats, a model of retinitis pigmentosa (Murakami et al., 2008).

PARP-1 activation in response to excessive DNA damage triggers the release of AIF from mitochondria and promotes PARP-1dependent cell death or parthanatos. AIF is a high-affinity PAR- 
binding protein. PAR-binding by AIF is required for its release from the mitochondria, translocation to the nucleus, and cell death (Wang et al., 2011). PARP activation and PAR accumulation have been linked to mitochondrial death and AIF translocation to the nucleus in photoreceptor cell death in rd1 mice (Paquet-Durand et al., 2007).

The other inflammatory mediator upregulated in these cultures, IL-6 is a pleiotropic cytokine with a role in inflammation, angiogenesis, cell differentiation and neuronal survival. In the retina, IL-6 is synthesized by Müller cells and the RPE (Benson et al., 1992; Yoshida et al., 2001). A neuroprotective role for IL-6 has been suggested in different animal models of ocular injury, in vitro studies, retinal vein occlusion, diabetic macular oedema and experimental glaucoma (Chong et al., 2008; Funatsu et al., 2009; Noma et al., 2009) suggesting that IL-6 upregulation after injury may serve to control photoreceptor apoptosis (Chong et al., 2008).

Retinal degeneration induced by PDE inhibition was accompanied by oxidative stress in porcine retina. Retina is normally protected from oxidative damage by the presence of enzymes such as superoxide dismutase and catalase (De La Paz et al., 1996). Photoreceptors, which are the predominant cell type in the retina, are particularly susceptible to free radical damage or lipid peroxidation (Osborne and Wood, 2004), because retinal photoreceptor membranes have an unusually high concentration of docosahexaenoic acid. Oxidative damage is a major factor contributing to cone cell death after the death of rods has occurred (Komeima et al., 2006; Shen et al., 2005). The increased levels of oxygen (hyperoxia), after death of rods result in progressive oxidative damage to cones in a transgenic pig model of RP and in multiple mouse models, including models of recessive and dominant RP. Antioxidant treatments can scavenger reactive oxygen species and promote cone survival and function (Komeima et al., 2006). In our study, we demonstrated the elevation of NO (NOX), which may increase peroxynitrite via the reaction the superoxide radical (Pryor and Squadrito, 1995). NO is an important regulator of homeostatic processes in the eye and its over-expression could contribute to pathological conditions in RP (Komeima et al., 2008).

We hypothesize that cGMP accumulation induces oxidative stress that probably induces microglial activation, as described in $r d$ mice, that in turns upregulates TNF-alpha contributing to the cell death. TNF-alpha can activate different cell death pathways including caspase-3, and PARP. On the other hand, cGMP accumulation leads to calcium influx and calpain activation. We believe that PDE6 inhibition activates more than one apoptotic pathway (caspase-dependent and caspase-independent) as occurs in other experimental models of retinal degeneration (Gómez-Vicente et al., 2005; Kaur et al., 2011). Moreover, our findings suggest that different retinal cell types follow different apoptotic pathways.

In summary, PDE6 mutations induce retinal degeneration in small animal models ( $r d 1, r d$ and $r d 10$ mice), but eye size and anatomic differences suggest that should be useful to have alternative models for studying retinal rescue strategies or design new drugs intended for humans. Porcine eyes are closer in size to human eyes and have a rich supply of rod and cones. Our organotypic culture of porcine cone-enriched retina exposed to Zaprinast may provide a helpful model to design and assay some treatments thus replacing or reducing animal experiments.

However, this kind of culture has its own limitations. Organotypic cell culturing involves transaction of the optic nerve and mechanical retinal detachment causing photoreceptor loss and retrograde retinal ganglion cell degeneration. To minimize this problem, use of detached samples as controls is necessary. In the future, we aim at improving the viability of organotypic cell cultures, although it is difficult to culture retinal neurons for long periods perhaps due to the high energy requirements of the retina.

\section{Uncited reference}

Tsai et al., 2009.

\section{Acknowledgements}

We thank Iván Fernández-Bueno (University of Valladolid, Instituto Universitario de Oftalmobiologia Aplicada (IOBA), Spain) for his help with the development of the retinal organotypic culture, Fany Belenchon and Carlos Vila (Unidad Veterinaria-Estabulación Centro de Investigación, Hospital La Fe, Valencia, Spain), Ana Díaz (Unidad Central de Investigación Facultad de Medicina y Odontología, Universidad de Valencia, Valencia, Spain), Juan Martín (Local Slaughterhouse MercaValencia, Valencia, Spain) for providing pig eyes and, Rafael Vázquez-Manrique for helping us with the confocal microscope (Sensory Organ Disorders, IIS-La Fe, Valencia). This work was supported by the European Regional Development Fund, Instituto de Salud Carlos III, PI08/90311 from the Ministerio de Ciencia e Innovación (MICINN) and AP-183/10 from the Conselleria de Sanitat de la Comunitat Valenciana. Regina Rodrigo has a Contrato-Investigador SNS Miguel Servet (CP09/118) from Instituto de Salud Carlos III (MICINN).

\section{References}

Allamby, D., Foreman, D., Carrington, L., McLeod, D., Boulton, M., 1997. Cell attachment to, and contraction of, the retina in vitro. Invest. Ophthalmol. Vis. Sci. 38 (10), 2064-2072.

Behnen, P., Dell'Orco, D., Koch, K.W., 2010. Involvement of the calcium sensor GCAP1 in hereditary cone dystrophies. Biol. Chem. 391 (6), 631-637.

Benson, M.T., Shepherd, L., Rees, R.C., Rennie, I.G., 1992. Production of interleukin-6 by human retinal pigment epithelium in vitro and its regulation by other cytokines. Curr. Eye Res. 11 (Suppl.), 173-179.

Bowes, C., Li, T., Danciger, M., Baxter, L.C., Applebury, M.L., Farber, D.B., 1990. Retinal degeneration in the rd mouse is caused by a defect in the beta subunit of rod cGMP-phosphodiesterase. Nature 347 (6294), 677-680.

Bredesen, D.E., Rao, R.V., Mehlen, P., 2006. Cell death in the nervous system. Nature 443, 796-802.

Buch, P.K., Mihelec, M., Cottrill, P., Wilkie, S.E., Pearson, R.A., Duran, Y., West, E.L. Michaelides, M., Ali, R.R., Hunt, D.M., 2011. Dominant cone-rod dystrophy: a mouse model generated by gene targeting of the GCAP1/Guca1a gene. PLoS One 28 (6(3)), e18089.

Burgess, A., Vigneron, S., Brioudes, E., Labbé, J.-C., Lorca, T., Castro, A., 2010. Loss of human Greatwall results in G2 arrest and multiple mitotic defects due to deregulation of the cyclin B-Cdc2/PP2A balance. Proc. Natl. Acad. Sci. U.S.A. 107, 12564-12569.

Burns, M.E., Mendez, A., Chen, J., Baylor, D.A., 2002. Dynamics of cyclic GMP synthesis in retinal rods. Neuron $36(1), 81-91$.

Chang, B., Hawes, N.L., Hurd, R.E., Davisson, M.T., Nusinowitz, S., Heckenlively, J.R. 2002. Retinal degeneration mutants in the mouse. Vision Res. 42 (4), 517525.

Chang, B., Grau, T., Dangel, S., Hurd, R., Jurklies, B., Sener, E.C., Andreasson, S. Dollfus, H., Baumann, B., Bolz, S., Artemyev, N., Kohl, S., Heckenlively, J., Wissinger, B., 2009. A homologous genetic basis of the murine cpfl1 mutant and human achromatopsia linked to mutations in the PDE6C gene. Proc. Natl. Acad. Sci. U.S.A. 17 (106(46)), 19581-19586.

Chong, D.Y., Boehlke, C.S., Zheng, Q.D., Zhang, L., Han, Y., Zacks, D.N., 2008. Interleukin-6 as a photoreceptor neuroprotectant in an experimental model of retinal detachment. Invest. Ophthalmol. Vis. Sci. 49 (7), 3193-3200.

Corbalán, R., Chatauret, N., Behrends, S., Butterworth, R.F., Felipo, V., 2002. Region selective alterations of soluble guanylate cyclase content and modulation in brain of cirrhotic patients. Hepatology 36, 1155-1162.

Corton, M., Blanco, M.J., Torres, M., Sanchez-Salorio, M., Carracedo, A., Brion, M., 2010. Identification of a novel mutation in the human PDE6A gene in autosoma recessive retinitis pigmentosa: homology with the $\mathrm{nmf} 28 / \mathrm{nmf} 28$ mice model. (Letter) Clin. Genet. 78, 495-498.

Daugas, E., Nochy, D., Ravagnan, L., et al., 2000. Apoptosis-inducing factor (AIF): a ubiquitous mitochondrial oxidoreductase involved in apoptosis. FEBS Lett. 476, $118-123$.

de Kozak, Y., Cotinet, A., Goureau, O., Hicks, D., Thillaye-Goldenberg, B., 1997. Tumor necrosis factor and nitric oxide production by resident retinal glial cells from rats presenting hereditary retinal degeneration. Ocul. Immunol. Inflamm. 5 (2), 85-94.

De La Paz, M.A., Zhang, J., Fridovich, I., 1996. Antioxidant enzymes of the human retina: effect of age on enzyme activity of macula and periphery. Curr. Eye Res. 15 (3), 273-278. 
Dizhoor, A.M., 2000. Regulation of cGMP synthesis in photoreceptors: role in signal transduction and congenital diseases of the retina. Cell. Signal. 12 (1112), 711-719.

Doonan, F., Donovan, M., Cotter, T.G., 2003. Caspase-independent photoreceptor apoptosis in mouse models of retinal degeneration. J. Neurosci. 23, 5723-5731.

Dryja, T.P. Rucinski, D.E. Chen, S.H. Berson, E.L. 1999. Frequency of mutations in the gene encoding the alpha subunit of rod cGMP-phosphodiesterase in autosoma recessive retinitis pigmentosa. Invest. Ophthalmol. Vis. Sci. 40 (8), 1859-1865.

Durrani, K., Ahmed, M., Foster, C.S., 2007. Adamantiades-Behcet disease: diagnosis and current concepts in management of ocular manifestations. Comp. Ophthalmol. Update 8 (4), 225-233.

El-Ghrably, I.A., Dua, H.S., Orr, G.M., Fischer, D., Tighe, P.J., 1999. Detection of cytokine mRNA production in infiltrating cells in proliferative vitreoretinopathy using reverse transcription polymerase chain reaction. Br. J. Ophthalmol. 83 (11), 1296-1299.

El-Mlili, N., Rodrigo, R., Naghizadeh, B., Cauli, O., Felipo, V., 2008. Chronic hyperammonemia reduces the activity of neuronal nitric oxide synthase in cerebellum by altering its localization and increasing its phosphorylation by calcium-calmodulin kinase II. J. Neurochem. 106 (3), 1440-1449.

Farber, D.B., Lolley, R.N., 1974. Cyclic guanosine monophosphate: elevation in degenerating photoreceptor cells of the C3H mouse retina. Science 186 (4162), $449-451$.

Fernandez-Bueno, I., Pastor, J.C., Gayoso, M.J., Alcalde, I., Garcia, M.T., 2008. Müller and macrophage-like cell interactions in an organotypic culture of porcine neuroretina. Mol. Vis. 14, 2148-2156.

Fisher, S.K., Lewis, G.P., 2003. Müller cell and neuronal remodeling in retinal detachment and reattachment and their potential consequences for visual recovery: a review and reconsideration of recent data. Vision Res. 43 (8), 887897.

Fox, D.A., Poblenz, A.T., He, L., 1999. Calcium overload triggers rod photoreceptor apoptotic cell death in chemical-induced and inherited retinal degenerations. Ann. N.Y. Acad. Sci. 893, 282-285.

Funatsu, H., Noma, H., Mimura, T., Eguchi, S., 2009. Hori. Association of vitreous inflammatory factors with diabetic macular edema. Ophthalmology 116 (1) $73-79$.

Gerke, C.G., Hao, Y., Wong, F., 1995. Topography of rods and cones in the retina of the domestic pig. HKMJ 1, 302-308.

Gómez-Vicente, V., Donovan, M., Cotter, T.G., 2005. Multiple death pathways in retina-derived $661 \mathrm{~W}$ cells following growth factor deprivation: crosstalk between caspases and calpains. Cell. Death Differ. 12, 796-804.

Grasl-Kraupp, B., Ruttkay-Nedecky, B., Koudelka, H., Bukowska, K., Bursch, W. Schulte-Hermann, R., 1995. In situ detection of fragmented DNA (TUNEL assay) fails to discriminate among apoptosis, necrosis, and autolytic cell death: a cautionary note. Hepatology 21 (5), 1465-1468.

Grau, T., Artemyev, N.O., Rosenberg, T., Dollfus, H., Haugen, O.H., Cumhur Sener, E. Jurklies, B., Andreasson, S., Kernstock, C., Larsen, M., Zrenner, E., Wissinger, B., Kohl, S., 2011. Decreased catalytic activity and altered activation properties of PDE6C mutants associated with autosomal recessive achromatopsia. Hum. Mol. Genet. 20 (4), 719-730.

Hendrickson, A., Hicks, D., 2002. Distribution and density of medium- and shortwavelength selective cones in the domestic pig retina. Exp. Eye Res. 74, 435444

Hisatomi, T., Sakamoto, T., Murata, T., Yamanaka, I., Oshima, Y., Hata, Y., Ishibashi, T. Inomata, H., Susin, S.A., Kroemer, G., 2001. Relocalization of apoptosis-inducing factor in photoreceptor apoptosis induced by retinal detachment in vivo. Am. J. Pathol. 158, 1271-1278.

Huang, S.H., Pittler, S.J., Huang, X., Oliveira, L., Berson, E.L., Dryja, T.P., 1995. Autosomal recessive retinitis pigmentosa caused by mutations in the alpha subunit of rod cGMP phosphodiesterase. Nat. Genet. 11 (4), 468-471.

Hunt, D.M., Buch, P., Michaelides, M., 2010. Guanylate cyclases and associated activator proteins in retinal disease. Mol. Cell. Biochem. 334 (1-2), 157-168.

Japiassú, R.M., Brasil, O.F., Cunha, A.L., de Souza, E.C., 2008. Regression of vasoproliferative tumor with systemic infliximab. Ophthal. Surg. Lasers Imaging 39 (4), $348-349$.

Jiang, L., Baehr, W., 2010. GCAP1 mutations associated with autosomal dominant cone dystrophy. Adv. Exp. Med. Biol. 664, 273-282.

Kalloniatis, M., Fletcher, E.L., 2004. Retinitis pigmentosa: understanding the clinical presentation, mechanisms and treatment options. Clin. Exp. Optom. 87 (2), 65-80.

Kaur, J., Mencl, S., Sahaboglu, A., Farinelli, P., van Veen, T., Zrenner, E., Ekström, P., Paquet-Durand, F., Arango-Gonzalez, B., 2011. Calpain and PARP activation during photoreceptor cell death in $\mathrm{P} 23 \mathrm{H}$ and S334ter rhodopsin mutant rats. PLoS One 6 (7), e22181.

Klein, R., Knudtson, M.D., Klein, B.E., Wong, T.Y., Cotch, M.F., Liu, K., Cheng, C.Y., Burke, G.L., Saad, M.F., Jacobs Jr., D.R., Sharrett, A.R., 2008. Inflammation, complement factor $\mathrm{h}$, and age-related macular degeneration: the Multi-ethnic Study of Atherosclerosis. Ophthalmology 115 (10), 1742-1749.

Koch, K.W., Stryer, L., 1988. Highly cooperative feedback control of retinal rod guanylate cyclase by calcium ions. Nature 334 (6177), 64-66.

Komeima, K., Rogers, B.S., Lu, L., Campochiaro, P.A., 2006. Antioxidants reduce cone cell death in a model of retinitis pigmentosa. Proc. Natl. Acad. Sci. U.S.A. 103 (30), 11300-11305.

Komeima, K., Usui, S., Shen, J., Rogers, B.S., Campochiaro, P.A., 2008. Blockade of neuronal nitric oxide synthase reduces cone cell death in a model of retinitis pigmentosa. Free Radic. Biol. Med. 45 (6), 905-912.
Kowluru, R.A., Kowluru, V., Xiong, Y., Ho, Y.S., 2006. Overexpression of mitochondrial superoxide dismutase in mice protects the retina from diabetes-induced oxidative stress. Free Radic. Biol. Med. 41 (8), 1191-1196.

Lorenzo, H.K., Susin, S.A., Penninger, J., Kroemer, G., 1999. Apoptosis inducing factor (AIF): a phylogenetically old, caspase- independent effector of cell death. Cell. Death Differ. 6, 516-524.

Maianski, N.A., Roos, D., Kuijpers, T.W., 2003. Tumor necrosis factor alpha induces a caspase-independent death pathway in human neutrophils. Blood 101 (5), 1987-1995.

McLaughlin, M.E., Sandberg, M.A., Berson, E.L., Dryja, T.P., 1993. Recessive mutations in the gene encoding the beta-subunit of rod phosphodiesterase in patients with retinitis pigmentosa. Nat. Genet. 4 (2), 130-134.

McLaughlin, M.E., Ehrhart, T.L., Berson, E.L., Dryja, T.P., 1995. Mutation spectrum of the gene encoding the beta subunit of rod phosphodiesterase among patients with autosomal recessive retinitis pigmentosa. Proc. Natl. Acad. Sci. U.S.A. 92 (8), 3249-3253.

Mizukoshi, S., Nakazawa, M., Sato, K., Ozaki, T., Metoki, T., Ishiguro, S., 2010. Activation of mitochondrial calpain and release of apoptosis-inducing factor from mitochondria in RCS rat retinal degeneration. Exp. Eye Res. 91 (3), 353-361.

Munemasa, Y., Kitaoka, Y., Kuribayashi, J., Ueno, S., 2010. Modulation of mitochondria in the axon and soma of retinal ganglion cells in a rat glaucoma model. J. Neurochem. 115 (6), 1508-1519.

Murakami, Y., Ikeda, Y., Yonemitsu, Y., Onimaru, M., Nakagawa, K., Kohno, R., Miyazaki, M., Hisatomi, T., Nakamura, M., Yabe, T., Hasegawa, M., Ishibashi, T., Sueishi, K., 2008. Inhibition of nuclear translocation of apoptosis-inducing factor is an essential mechanism of the neuroprotective activity of pigment epithelium-derived factor in a rat model of retinal degeneration. Am. J. Pathol. $173(5), 1326-1338$.

Murray, P.I., Hoekzema, R., van Haren, M.A., de Hon, F.D., Kijlstra, A., 1990. Aqueous humor interleukin-6 levels in uveitis. Invest. Ophthalmol. Vis. Sci. 31 (5), 917-920.

Nagata, S., 1997. Apoptosis by death factor. Cell 88, 355-365.

Nakazawa, T., Matsubara, A., Noda, K., Hisatomi, T., She, H., Skondra, D., Miyahara, S., Sobrin, L., Thomas, K.L., Chen, D.F., Grosskreutz, C.L., Hafezi-Moghadam, A., Miller, J.W., 2006. Characterization of cytokine responses to retinal detachment in rats. Mol. Vis. 12, 867-878.

Nakazawa, M., 2011. Effects of calcium ion, calpains, and calcium channel blockers on retinitis pigmentosa. J. Ophthalmol. 2011, 292040.

Nakazawa, T., Kayama, M., Ryu, M., Kunikata, H., Watanabe, R., Yasuda, M., Kinugawa, J., Vavvas, D., Miller, J.W., 2011. Tumor necrosis factor-alpha mediates photoreceptor death in a rodent model of retinal detachment. Invest. Ophthalmol. Vis. Sci. 52 (3), 1384-1391.

Noma, H., Funatsu, H., Mimura, T., Harino, S., Hori, S., 2009. Vitreous levels of interleukin-6 and vascular endothelial growth factor in macular edema with central retinal vein occlusion. Ophthalmology 116 (1), 73-79.

Osborne, N.N., Wood, J.P., 2004. Metipranolol blunts nitric oxide-induced lipid peroxidation and death of retinal photoreceptors: a comparison with other anti-glaucoma drugs. Invest. Ophthalmol. Vis. Sci. 45 (10), 3787-3795.

Paquet-Durand, F., Silva, J., Talukdar, T., Johnson, L.E., Azadi, S., van Veen, T., Ueffing, M., Hauck, S.M., Ekström, P.A., 2007. Excessive activation of poly(ADPribose) polymerase contributes to inherited photoreceptor degeneration in the retinal degeneration 1 mouse. J. Neurosci. 27 (38), 10311-10319.

Paquet-Durand, F., Hauck, S.M., van Veen, T., Ueffing, M., Ekström, P., 2009. PKG activity causes photoreceptor cell death in two retinitis pigmentosa models. J. Neurochem. 108 (3), 796-810.

Paquet-Durand, F., Sanges, D., McCall, J., Silva, J., van Veen, T., Marigo, V., Ekström, P., 2010. Photoreceptor rescue and toxicity induced by different calpain inhibitors. J. Neurochem. 115 (4), 930-940.

Perrault, I., Rozet, J.M., Calvas, P., Gerber, S., Camuzat, A., Dollfus, H., Châtelin, S. Souied, E., Ghazi, I., Leowski, C., Bonnemaison, M., Le Paslier, D., Frézal, J., Dufier,J.L., Pittler, S., Munnich, A., Kaplan, J., 1996. Retinal-specific guanylate cyclase gene mutations in Leber's congenital amaurosis. Nat. Genet. 14 (4), 461-464.

Perrault, I., Rozet, J.M., Gerber, S., Ghazi, I., Ducroq, D., Souied, E., Leowski, C., Bonnemaison, M., Dufier, J.L., Munnich, A., Kaplan, J., 2000. Spectrum of retGC1 mutations in Leber's congenital amaurosis. Eur. J. Hum. Genet 8 (8), 578-582.

Petersen-Jones, S.M., Entz, D.D., Sargan, D.R., 1999. cGMP phosphodiesterase-alpha mutation causes progressive retinal atrophy in the Cardigan Welsh corgi dog. Invest. Phthalmol. Vis. Sci. 40 (8), 1637-1644.

Piri, N., Gao, Y.Q. Danciger, M. Mendoza, E., Fishman, G.A., Farber, D.B., 2005. A substitution of $\mathrm{G}$ to $\mathrm{C}$ in the cone CGMP-phosphodiesterase gamma subunit gene found in a distinctive form of cone dystrophy. Ophthalmology 112 (1), $159-166$.

Pryor, W.A., Squadrito, G.L., 1995. The chemistry of peroxynitrite: a product from the reaction of nitric oxide with superoxide. Am. J. Physiol. 268 (5 Pt 1), L699-L722.

Sahaboglu, A., Tanimoto, N., Kaur, J., Sancho-Pelluz, J., Huber, G., Fahl, E., ArangoGonzalez, B., Zrenner, E., Ekström, P., Löwenheim, H., Seeliger, M., PaquetDurand, F., 2010. PARP1 gene knock-out increases resistance to retinal degeneration without affecting retinal function. PLoS One 5 (11), e15495

Sakamoto, K., McCluskey, M., Wensel, T.G., Naggert, J.K., Nishina, P.M., 2009. New mouse models for recessive retinitis pigmentosa caused by mutations in the Pde6a gene. Hum. Mol. Genet. 18 (1), 178-192.

Sanges, D., Comitato, A., Tammaro, R., Marigo, V., 2006. Apoptosis in retinal degeneration involves cross-talk between apoptosisinducing factor (AIF) and caspase- 12 and is blocked by calpain inhibitors. Proc. Natl. Acad. Sci. U.S.A. 103, 17366-17371. 
Sargan, D.R., Clements, P.J., Sohal, A., Gregory, C.Y., Bhattacharya, S.S., PetersenJones, S.M., 1994. Progressive retinal atrophy: a model for retinitis pigmentosa in companion animals. Gene Ther. 1 (Suppl. 1), S89.

Seddon, J.M., George, S., Rosner, B., Rifai, N., 2005. Progression of age-related macular degeneration: prospective assessment of C-reactive protein, interleukin 6 , and other cardiovascular biomarkers. Arch. Ophthalmol. 123 (6), 774-782.

Sharma, A.K., Rohrer, B., 2004. Calcium-induced calpain mediates apoptosis via caspase-3 in a mouse photoreceptor cell line. J. Biol. Chem. 279 (34), 3556435572.

Sharma, A.K., Rohrer, B., 2007. Sustained elevation of intracellular cGMP causes oxidative stress triggering calpain-mediated apoptosis in photoreceptor degeneration. Curr. Eye Res. 32 (3), 259-269.

Shen, J., Yang, X., Dong, A., Petters, R.M., Peng, Y.W., Wong, F., Campochiaro, P.A., 2005. Oxidative damage is a potential cause of cone cell death in retinitis pigmentosa. J. Cell. Physiol. 203 (3), 457-464.

Sokal, I., Dupps, W.J., Grassi, M.A., Brown Jr., J., Affatigato, L.M., Roychowdhury, N., Yang, L., Filipek, S., Palczewski, K., Stone, E.M., Baehr, W., 2005. A novel GCAP1 missense mutation (L151F) in a large family with autosomal dominant cone-rod dystrophy (adCORD). Invest. Ophthalmol. Vis. Sci. 46 (4), 1124-1132.

Stieger, K., Lhériteau, E., Moullier, P., Rolling, F., 2009. AAV-mediated gene therapy for retinal disorders in large animal models. ILAR J. 50 (2), 206-224.

Suber, M.L., Pittler, S.J., Qin, N., Wright, G.C., Holcombe, V., Lee, R.H., Craft, C.M., Lolley, R.N., Baehr, W., Hurwitz, R.L., 1993. Irish setter dogs affected with rod/ cone dysplasia contain a nonsense mutation in the rod cGMP phosphodiesterase beta-subunit gene. Proc. Natl. Acad. Sci. U.S.A. 90 (9), 3968-3972.

Suo, G.J., Qin, J., Zhong, C.P., Zhao, Z.X., 2010. Suppressor of cytokine signaling 1 inhibits apoptosis of islet grafts through caspase 3 and apoptosis-inducing factor pathways in rats. Transplant. Proc. 42 (7), 2658-2661.

Tezel, G., Yang, X., 2004. Caspase-independent component of retinal ganglion cell death, in vitro. Invest. Ophthalmol. Vis. Sci. 45 (11), 4049-4059.

Thapa, A., Morris, L., Xu, J., Ma, H., Michalakis, S., Biel, M., Ding, X.Q., 2012. Endoplasmic reticulum stress-associated cone photoreceptor degeneration in cyclic nucleotide-gated channel deficiency. J. Biol. Chem. 287 (22), 18018-18029.

Thiadens, A.A., den Hollander, A.I., Roosing, S., Nabuurs, S.B., Zekveld-Vroon, R.C., Collin, R.W., De Baere, E., Koenekoop, R.K., van Schooneveld, M.J., Strom, T.M., van Lith-Verhoeven, J.J., Lotery, A.J., van Moll-Ramirez, N., Leroy, B.P., van den Born, L.I., Hoyng, C.B., Cremers, F.P., Klaver, C.C., 2009. Homozygosity mapping reveals PDE6C mutations in patients with early-onset cone photoreceptor disorders. Am. J. Hum. Genet. 85 (2), 240-247.

Tsai, G.Y., Cui, J.Z., Syed, H., Xia, Z., Ozerdem, U., McNeill, J.H., Matsubara, J.A., 2009. Effect of $\mathrm{N}$-acetylcysteine on the early expression of inflammatory markers in the retina and plasma of diabetic rats. Clin. Exp. Ophthalmol. 37, 223-231.
Tucker, C.L., Woodcock, S.C., Kelsell, R.E., Ramamurthy, V., Hunt, D.M., Hurley, J.B., 1999. Biochemical analysis of a dimerization domain mutation in RetGC-1 associated with dominant cone-rod dystrophy. Proc. Natl. Acad. Sci. U.S.A. 96 (16), 9039-9044.

Tuntivanich, N., Pittler, S.J., Fischer, A.J., Omar, G., Kiupel, M., Weber, A., Yao, S., Steibel, J.P., Khan, N.W., Petersen-Jones, S.M., 2008. Characterization of a canine model of autosomal recessive retinitis pigmentosa due to a PDE6A mutation. Invest. Ophthalmol. Vis. Sci. 50 (2), 801-813, 2009.

Vallazza-Deschamps, G., Cia, D., Gong, J., Jellali, A., Duboc, A., Forster, V., Sahel, J.A. Tessier, L.H., Picaud, S., 2005. Excessive activation of cyclic nucleotide-gated channels contributes to neuronal degeneration of photoreceptors. Eur. J. Neurosci. 22 (5), 1013-1022.

Wang, W., Acland, G.M., Ray, K., 1999. Aguirre GD Evaluation of cGMPphosphodiesterase (PDE) subunits for causal association with rod-cone dysplasia $2(\operatorname{rcd} 2)$, a canine model of abnormal retinal cGMP metabolism. Exp. Eye Res. 69 (4), 445-453.

Wang, Y., Kim, N.S., Haince, J.F., Kang, H.C., David, K.K., Andrabi, S.A., Poirier, G.G., Dawson, V.L., Dawson, T.M., 2011. Poly(ADP-ribose) (PAR) binding to apoptosisinducing factor is critical for PAR polymerase-1-dependent cell death (parthanatos). Sci. Signal. 5 (4(167)), ra20.

Winkler, J., Hagelstein, S., Rohde, M., Laqua, H., 2002. Cellular and cytoskeletal dynamics within organ cultures of porcine neuroretina. Exp. Eye Res. 74 (6), 777-788.

Yang, L.P., Zhu, X.A., Tso, M.O., 2007. A possible mechanism of microgliaphotoreceptor crosstalk. Mol. Vis. 13, 2048-2057.

Yoshida, S., Sotozono, C., Ikeda, T., Kinoshita, S., 2001. Interleukin-6 (IL-6) production by cytokine-stimulated human Muller cells. Curr. Eye Res. 22 (5), 341-347.

Yoshida, N., Ikeda, Y., Notomi, S., Ishikawa, K., Murakami, Y., Hisatomi, T., Enaida, H., Ishibashi, T., 2013a. Clinical evidence of sustained chronic inflammatory reaction in retinitis pigmentosa. Ophthalmology 120 (1), 100-105.

Yoshida, N., Ikeda, Y., Notomi, S., Ishikawa, K., Murakami, Y., Hisatomi, T., Enaida, H., Ishibashi, T., 2013b. Laboratory evidence of sustained chronic inflammatory reaction in retinitis pigmentosa. Ophthalmology 120 (1), e5-e12.

Yoshizawa, K., Kiuchi, K., Nambu, H., et al., 2002. Caspase-3 inhibitor transiently delays inherited retinal degeneration in $\mathrm{C} 3 \mathrm{H}$ mice carrying the rd gene. Graefes Arch. Clin. Exp. Ophthalmol. 240 (3), 214-219.

Zeiss, C.J., Neal, J., Johnson, E.A., 2004. Caspase-3 in postnatal retinal development and degeneration. Invest. Ophthalmol. Vis. Sci. 45, 964-970.

Zhang, X., Feng, Q., Cote, R.H., 2005. Efficacy and selectivity of phosphodiesterasetargeted drugs in inhibiting photoreceptor phosphodiesterase (PDE6) in retinal photoreceptors. Invest. Ophthalmol. Vis. Sci. 46 (9), 3060-3066. 